\title{
A AUTOAVALIAÇÃO INSTITUCIONAL NO PROCESSO DE TOMADA DE DECISÃO EM IES: ESTUDO DE CASO DAS FACULDADES SENAC/SC
}

\author{
Elita Grosch MabA* \\ SidNEI VIEIRA MARINHO**
}

Recebido: 03 ago. 2011

Aprovado: 22 set. 2012

\begin{abstract}
* Mestre em Administração pela Universidade do Vale do Itajaí. Diretora da Faculdade SENAC Blumenau (SC).E-mail: elita@sc.senac.br

${ }^{* *}$ Doutor em Engenharia de Produção pela Universidade Federal de Santa Catarina. Professor do Programa de Mestrado e Doutorado em Administração da Universidade do Vale do Itajaí. E-mail: sidnei@univali.br
\end{abstract}

Resumo: O presente artigo pretende demonstrar em seu contexto a relação existente entre o sistema de autoavaliação institucional e o processo de tomada de decisão, especificamente nas Faculdades de Tecnologia pertencentes à Administração Regional do SENAC-SC. Utilizando uma amostra intencional deste universo, o estudo, realizado em 2010, é caracterizado como descritivo-exploratório, do tipo quali-quantitativo, mediante a aplicação de uma pesquisa bibliográfico-documental, configurada como um estudo multicaso. Nas seis unidades investigadas, foram entrevistados: o diretor da unidade e os coordenadores de áreas (Núcleo Relações com o Mercado, Núcleo Administrativo Financeiro e Núcleos Educacional Básico e do Ensino Superior), aplicando-se um questionário estruturado com questões abertas e fechadas, permitindo a avaliação de aspectos objetivos e quantificáveis e subjetivo-discursivos. Os resultados apontam para a autoavaliação institucional como facilitadora do processo decisório, provendo informações que permitem avaliar determinada situação. Adicionalmente, identificam os pontos fortes e fracos da IES e que melhoram a qualidade das decisões estratégicas, o que confirma a existência da relação pressuposta acima, bem como a importância do processo de autoavaliação institucional. Mostram, ainda, a necessidade de revisão da estrutura, visando aprimorar a apropriação dos dados levantados pela autoavaliação e aplicados como suporte no processo de tomada de decisão das instituições do universo analisado. Por fim, a hipótese de pesquisa, em base a esses resultados, acabou sendo validada, ratificando tal relação.

Palavras-Chave: Autoavaliação institucional. Tomada de decisão. Qualidade. Educação tecnológica.

\section{INSTITUTIONAL SELF-EVALUATION IN THE DECISION-MAKING PROCESS AT HEIs: A CASE STUDY OF SENAC/SC HIGHER EDUCATION SCHOOL}

Abstract: This article presents, briefly, the master thesis that gave rise and that analyzes the institutional selfevaluation and the decision-making process at SENAC-SC and the relationship between them. By using an intentional sample of six technology universities belonging to the regional administration of SENAC-SC, this research, carried out in June and July 2010 (cross-sectional basis, i.e., during the current year), had the main purpose of analyzing the institutional self-evaluation and its influence over the decision-making process, supplemented by its specific purposes that were: describe these two processes; identify the appropriation of the results from the institutional self-evaluation in the SENAC-SC universities; and list and discuss those elements that either make it easier or difficult to appropriate such results in the decision-making process within the institution. The study was characterized as a qualitative/quantitative-type descriptive-exploratory study upon the application of a bibliographic-documentary research configured as a multi-case study. Interviews were carried out at each investigated university with: The director of the unit and the area coordinators (market relationship core, administrative/financial core and basic and superior education core), who are understood as the managers of these institutions. A structured questionnaire was applied, containing open and closed-type questions, in the mentioned period, in order to evaluate not only objective 
and aspects, but also subjective-discursive aspects. The main results have confirmed the existence of the above-assumed relationship, including the importance of the institutional self-evaluation process. In addition and in attention to the specific goals, they indicate that notwithstanding such importance, its structure needs to be revised in order to improve such relationship and improve the appropriation of the surveyed data by the self-evaluation and apply them as an auxiliary means for the decision-making process of the universities in the analyzed universe. The research hypothesis, which was predicting that the institutional self-evaluation, when established in an institution, influences with the provision of subsidies, the decision-making process, was validated by the results.

Key words: Institutional self-evaluation. Decision making. Quality. Technological education.

\section{INTRODUÇÃO}

Dentro da teoria administrativo-organizacional vigente nas instituições de Educação Superior (IES), existem vários instrumentos que permitem monitorar, detectar e corrigir as ações de gestão e operacionais numa organização, com vistas a melhorar seu desempenho e torná-la mais competitiva. Um desses instrumentos é a avaliação institucional interna (ou autoavaliação), a qual, segundo Cardoso, Santos e Figueiredo (2002, p. 3), "é um ciclo, entendido sistemático e regular, de revisão das atividades e resultados da organização em relação a um modelo de excelência, culminando em ações melhor planejadas".

É dentro deste cenário de Ensino Superior com qualidade que se propôs analisar a existência de uma relação estreita entre a autoavaliação institucional das IES e seus processos de tomada de decisão, no sentido daquela servir como provedora de informações importantes para estes processos, alimentando-os periodicamente com dados atualizados que permitem as necessárias correções de rota nos temas estratégicos que demandam acurada decisão.

A pesquisa concentrou-se na área de Ensino Tecnológico (os chamados Cursos Superiores de Tecnologia - CST), cuja formação de tecnólogos representa a aproximação entre a academia e o trabalho (DUCH, 2010), ajustando e atualizando as tendências, novas normas e condições gerais dessa relação. Dados demonstram o crescimento visível destes cursos, indicando sua importância para o mercado de trabalho, hoje claramente mais dinâmico em suas mudanças (BRASIL-INEP, 2009; MARTINS; GARIBA JUNIOR, 2006).

Para tal propósito, definiu-se uma amostra de seis faculdades de tecnologia pertencentes ao Serviço Nacional de Aprendizagem Comercial (SENAC) do estado de Santa Catarina, escolhidas com base no perfil similar apresentado por estas, bem como também à disponibilidade dos gestores das diversas áreas estratégicas que seriam entrevistados. $\mathrm{O}$ estudo teve foco em torno da seguinte questão-problema: Considerando-se que a autoavaliação institucional, 
segundo a literatura pertinente, influencia no processo de tomada de decisão das IES, pergunta-se: (a) Há indicadores precisos dessa influência no processo decisório das IES? (b) Se a resposta à questão anterior for positiva, como se dá essa influência? Como hipótese (classificada como indutiva e analógica) a ser corroborada ou refutada, definiu-se o seguinte: A autoavaliação institucional, quando implantada em uma Instituição, influencia, com a provisão de subsídios, o processo de tomada de decisão.

\section{REVISÃO DA LITERATURA}

A administração organizacional de uma Instituição de Ensino Superior, assim como também seu planejamento estratégico, são tarefas complexas, principalmente nestes tempos de grandes mudanças tecnológicas, sociais e políticas (ELPO, 2004; KRASILCHIK, 2008). Essa complexidade pode estar associada ao "produto final" da educação, ou seja, a formação profissional-tecnológica do indivíduo, o que lhe permite maior criticidade. "Na administração da educação, as funções básicas de estabelecimento de políticas e de gestão da educação assim como a resultante organização e funcionamento das instituições educacionais são fatores decisivos no desempenho e no nível de qualidade de sua prática" (WITTMANN; GRACINDO, 2001, p. 11). Esses níveis de criticidade, por sua vez, são maximizados pela diversidade classificatória das universidades; o ensino de $3^{\circ}$ grau - ou "ecossistema universitário brasileiro" - está composto, hoje, por vários tipos de instituições: universidades públicas federais, estaduais e municipais; escolas técnicas (como as faculdades de tecnologia); universidades privadas confessionais; universidades particulares; centros universitários (ibidem), o que redunda em afirmar que são diferentes e diversos os projetos estratégicos, embora coincidam em sua divisão de cenário mercadológico, ou seja, em curto, médio e longo prazo. Além disso, para cada um desses planos ou projetos, há a necessidade de se definirem planos alternativos (contingenciais) para o enfrentamento de eventuais mudanças de rota demandadas pelo mercado mutante (ibidem).

Um fator fundamental para todo o processo administrativo universitário é o rol de desafios interpostos pelo novo contexto de informação e conhecimento, o que tem levado os gestores a se atualizarem no manejo das novas tecnologias. "A revolução contemporânea da informação e do conhecimento conduz a uma série de demandas das IES, tanto em função de suas relações externas como no concernente às lides da docência e da investigação" (BRUNNER, 2002, p. 10). Este novo cenário mostra que as IES perderam seu monopólio informacional, 
sendo levadas a trabalhar num ambiente saturado de informação: “A Galáxia Gutenberg cede passagem à Galáxia Internet, na qual a informação avançada se encontra distribuída nas redes eletrônicas, particularmente através da Internet" (BRUNNER, 2002, p. 10). Esta constatação, associada às dimensões planetárias da Internet, pressupõe um complicador a mais no processo administrativo, no sentido da confiabilidade das fontes e das informações geradas por estas - como base para as decisões do administrador.

A essa complexa equação se soma a questão da qualidade na educação. $\mathrm{O}$ crescimento da demanda pelo terceiro grau (seja acadêmico ou tecnológico) fez também crescer, proporcionalmente, o número de IES, trazendo sérios problemas de qualidade educativa e, por decorrência, prejudicando o resultado do binômio "ensino x aprendizagem" (BRUNNER, 2002). É neste momento que Brunner (2002, p. 8) traz à baila os instrumentos que podem propiciar a tão desejada qualidade, afirmando:

A massificação da demanda e do acesso conduzem mesmo assim à necessidade de estabelecer mecanismos para assegurar a qualidade da oferta pública e privada de educação superior (sistemas de informação, controle, exame, avaliação e credenciamento), como se tem implementado em Argentina, Brasil, Chile, Colômbia, El Salvador e México e começam a ser adotados noutros países da região. O desenvolvimento destes sistemas de garantia da qualidade traz em si demandas complementares sobre as IES, gerando-se uma crescente pressão avaliativa sobre as mesmas, a necessidade de autoavaliação, obrigação legal de submeterem-se a processos de credenciamento, demandas de accountability, o emprego de indicadores de desempenho, a conveniência de obter um credenciamento de prestigio por entidades do estrangeiro e a exigência de competir em função de resultados e, de maneira incipiente, pela colocação em rankings de instituições y programas.

É em decorrência dessa necessária (e obrigatória, até) qualidade educativa que os sistemas de avaliação e de autoavaliação passaram a ocupar maior espaço, tanto nas IES como nas discussões atinentes à gestão universitária.

\subsection{Avaliação institucional}

O marco teórico da avaliação educacional institucional parte das ideias de Ralph Tyler que, durante o período de 1929 a 1938, colaborava com o Bureau of Educational Research and Service da Ohio State University (USA) onde sua 
principal atividade "envolvia a assistência aos professores através da Universidade a fim de avaliar seus cursos com o objetivo de melhoramento destes, bem como o do sistema de aprendizagem do estudante" (TYLER; MADAUS; STUFFLEBEAM, 1989, p. 3). Tyler, neste seu labor, constrói o primeiro método sistemático de avaliação educacional, “dando início à consolidação da avaliação educacional, como campo teórico e prático da educação a partir da discussão da construção e da implementação do currículo escolar" (DA SILVA, 2007, p. 191).

Gatti (2006, p. 321), por seu turno, amplia a compreensão de avaliação institucional aduzindo a que esta, além de analisar questões científico-técnicas e de produtos, alcança temas como a gestão e todo o rol de temas transversais que a acompanham, "uma vez que seu eixo é o estudo da efetividade da ação institucional como um todo". A avaliação, segundo esta autora, parte de perspectivas que dizem respeito ao sentido e significado da IES em seu entorno, considerando, ainda, aspectos do seu planejamento e dos seus projetos de trabalho, ensino e pesquisa, bem como da efetiva implementação destes, aos quais está associada uma expectativa de valor adicional ao trabalho institucional desenvolvido. E acrescenta:

Portanto, estando a instituição universitária no seio de uma comunidade mais ampla, estando ao mesmo tempo a serviço dela e pensando/ promovendo mudanças societárias, tem seus fundamentos em uma perspectiva sociocultural e ética, para além de seu papel científico (p. 321).

Em relação aos quatro tipos de modelos avaliativos, Gatti (2006, p. 322) os classifica assim, desde já salientando que eles não são excludentes entre si, mas há que se ressalvar que apenas os dois últimos atendem as novas perspectivas na avaliação institucional:

- Modelos descritivos - Coleta de dados que caracterizam a instituição mediante aplicação de questionários, cujas respostas permitem traçar um perfil sobre várias variáveis;

- Modelos descritivo-analíticos - Comparam ou cruzam variáveis derivadas dos processos internos e dos produtos;

- Modelos reflexivo-interpretativos - Partem de uma base descritiva e analítica, "avançam interpretações, traduzindo significados e relevâncias, a partir de referentes sociocientífico-culturais", o que lhes permite agregar 
"formas diversificadas de coleta de dados como entrevistas, individuais ou coletivas, observação, grupos focais, estudos de caso etc., contemplando os vários nichos organizacionais";

- Modelos reflexivo-participativos - Possuem apoio em premissas e formas de coleta da avaliação participativa, envolvendo "situação de reflexão sobre as formas e os processos de desenvolvimento das diversas atividades institucionais", além dos "vários segmentos co-participes em diálogos reflexivo-interpretativos das representações e significados dessas ações e seus impactos percebido ou possível".

A avaliação de IES, portanto, atende em seu principal objetivo conhecer a real situação da instituição, apontando-lhe eventuais melhorias ou correções de rumo. Com o advento do SINAES, concebido em 2003 pela Comissão Especial de Avaliação da Educação Superior (CEA), por norma das Portarias MEC/ Sesu de $n^{\circ} 11$ (28.04.2003) e de $n^{\circ} 19$ (27.05.2003), a avaliação institucional passou a ter os objetivos de "analisar, oferecer subsídios, fazer recomendações, propor critérios e estratégias para a reformulação dos processos e políticas de avaliação da Educação Superior e elaborar a revisão crítica dos seus instrumentos, metodologias e critérios utilizados", consoante determinação do próprio MEC (MARBACK NETO, 2007, p. 193). É oportuno, ainda, mencionar que a sistemática de avaliação institucional estabelecida pelo SINAES (criado pela Lei $n^{\circ}$ 10.861/2004, que também institui a CONAES - Comissão Nacional de Avaliação do Ensino Superior - a quem cabe a coordenação e supervisão do SINAES, e as Comissões Próprias de Avaliação - CPAs, nos níveis locais) (MARBACK NETO, 2007; ARAÚJO, CORREIA, 2005), foi construída com base em três processos de avaliação (BRASIL, 2004, p.13): “Avaliação da Instituição (Autoavaliação e Avaliação Externa); Exame Nacional de Desempenho dos Estudantes (ENADE); Avaliação dos Cursos de Graduação". A Comissão Própria de Avaliação (CPA) possui a função de "elaborar o instrumento de avaliação externa para fins de credenciamento de universidades" (MARBACK NETO, 2007, p. 194; ARAÚJO; CORREIA, 2005, p. 114).

Assim, o processo avaliativo pode ser entendido como sendo uma ferramenta de gestão que possibilita a melhoria contínua dos processos organizacionais, ademais de ser, como visto, uma exigência da legislação vigente, nas diretrizes institucionais, possibilitando mensurar indicadores e melhorar o processo educacional - isto sem esquecer-se do resultado incidente sobre a qualidade do 
ensino oferecido ao aluno. Dias Sobrinho (2003, p. 31-32), no entanto, esclarece a confusão que se faz entre regulação e avaliação, orientando a adequada compreensão desses termos:

As ações de regulação - entendida equivocadamente como "avaliação" - se desenvolvem como parte essencial da agenda de modernização e privatização, em que as instituições educativas são levadas a adotar mentalidades, práticas e formas de organizações voltadas a seus interesses próprios e privados. Duas outras características têm aí papel de grande importância: a transnacionalização e a funcionalização econômica da educação e, portanto, da avaliação da educação superior.

De acordo com Sguissardi (1997), cabe à instituição apresentar claramente seus objetivos, utilizar-se de tecnologias seguras para que haja coerência e vinculação entre aquilo que planeja e o que desenvolve, atuando dentro de sua política de desenvolvimento com resultados plausíveis. Porém, é preciso que todo o processo esteja estritamente vinculado e encadeado com a especificidade da atividade universitária, usufruindo da liberdade e autonomia de decisão sobre o quê e como ensinar e pesquisar, talvez sendo este o verdadeiro caráter e sentido de constituição da universidade.

\subsection{Autoavaliação institucional}

Dentro da teoria administrativo-organizacional, existem vários instrumentos que permitem monitorar, detectar e corrigir as ações de gestão e operacionais numa organização, com vistas a melhorar seu desempenho e torná-la mais competitiva. Um desses instrumentos é a avaliação institucional interna (ou autoavaliação), um processo de avaliação permanente e objetivo, que alcança todos os segmentos da instituição (corpos docente, discente e técnico-administrativo; biblioteca; laboratórios; equipamentos; infra-estruturas físicas e tecnológicas; organização didático-pedagógica); seu objetivo é "identificar distorções e falta de eficiência para as necessárias correções de rumo visando sempre à implantação de um ensino de qualidade" (MURIEL, 2006, p. 175). Este enfoque possui relação estreita com requisitos de qualidade e estratégias de treinamento (MENESES; ABBAD, 2003; SANTOS; ROLIM, 1999), vez que, adotando um modelo de excelência que se mostre adequado a atender as necessidades, desejos e expectativas de uma organização, os parâmetros para tal propiciarão o desenvolvimento de programas destinados à melhoria 
da qualidade, através do treinamento e das estratégias de ajustes advindas do processo avaliativo.

A avaliação institucional interna (autoavaliação) também é uma ferramenta institucional com caráter pedagógico, que objetiva a busca de melhorias e auto-regulação, bem como compreensão da cultura e da vida institucional em sua pluralidade acadêmica e administrativa. Ditos objetivos são amparados na participação dos agentes universitários, por ser um processo social e coletivo de reflexão, produção e socialização dos conhecimentos sobre a IES com indicador da ação transformadora. Segundo Dias Sobrinho (2000, p. 107-108):

[...] embora seja mais fácil separar para conhecer, e ainda que seja necessário fragmentar no processo de conhecimento, na avaliação institucional é preciso ir além e buscar a significação de conjunto e em conjunto. [...] É insuficiente levantar os dados, torná-los visíveis; mais do que isso, é preciso selecioná-los pelos critérios de pertinência e relevância, interpretá-los, refletir sobre sua significação, buscando sempre a compreensão de conjunto.

O desenvolvimento da "avaliação das instituições" corresponde ao primeiro eixo temático do SINAES, e seu principal objetivo é verificar a constituição das IES, sua capacidade de atendimento à comunidade acadêmica de forma geral (POLIDORI et al, 2006, p. 431); neste item está incluso "um dos pontos mais importantes do sistema avaliativo: o desenvolvimento do processo de autoavaliação". A avaliação da instituição tem sua primeira etapa na realização da autoavaliação e é complementada pela avaliação externa in loco.

A Figura 1 expõe um desenho geral do sistema de autoavaliação institucional. Observa-se nesta figura que o processo avaliativo se desdobra (diagnóstico / prognóstico), o que dá lugar ao planejamento que, por sua vez, divide a avaliação em somativa (produto) e reguladora (gestão-implementação).

A função de avaliar deve primeiramente ser a procura do autoconhecimento (autoavaliação), possibilitando a edificação de uma cultura de avaliação na IES e permitindo que se organizem e gerem condições para encarar as diferentes avaliações externas realizadas na instituição, em especial ao processo de avaliação de cursos. Porém, não significa que devam adaptar-se ao modelo de avaliação externa, e sim, criar uma cultura de autoavaliação e de reflexão-ação-reflexão indispensáveis para o crescimento e progresso de uma IES (POLIDORI et al, 2006). 
Figura 1 - Sistema de Autoavaliação Institucional

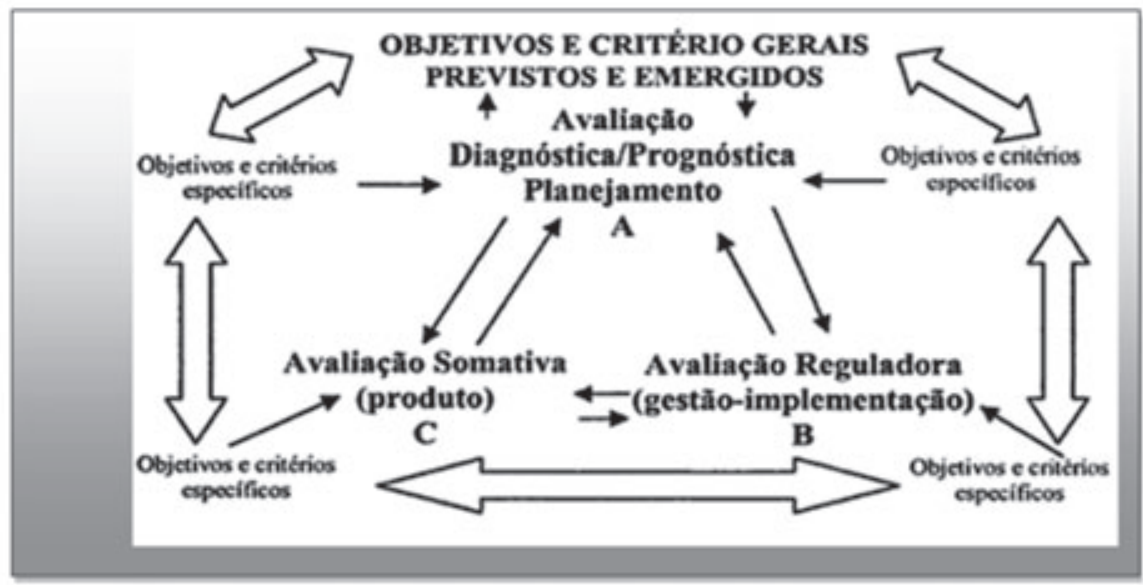

Fonte: Da Silva (2007, p. 247).

Furtado e Furtado (2000, p. 121) parafraseiam os ensinamentos de Luckesi (1994) para quem a autoavaliação é "um ato subsidiário do processo de construção de resultados satisfatórios"; ela "acolhe alguma coisa, ato, pessoa ou situação e, então, reconhece-a como é (diagnóstico), para uma tomada de decisão sobre a possibilidade de uma melhoria de sua qualidade". Assim vista, a autoavaliação seria um movimento no sentido prática $\rightarrow$ teoria $\rightarrow$ prática já que considera "o processo educativo a partir da ação, levando em conta o domínio teórico como as habilidades que vão sendo construídas pelos atores no processo". Furtado e Furtado (2000, p. 121) entendem, ainda, que os preceitos teóricos da autoavaliação possuem base de sustentação no processo ação $\rightarrow$ reflexão $\rightarrow$ ação, já que, teoricamente, toda ação gera uma reflexão.

As dimensões da autoavaliação institucional seguem, a exemplo da avaliação institucional, as dimensões ditadas pelo SINAES (CUNHA, 2005, p. 205), a saber:

- Missão e plano de desenvolvimento institucional;

- Política de ensino, pesquisa, pós-graduação e extensão;

- Responsabilidade social da IES;

- Comunicação com a sociedade;

- $\quad$ Políticas de pessoal, de carreira do corpo docente e técnico-administrativo, seu aperfeiçoamento e condições de trabalho;

- $\quad$ Organização e gestão da instituição;

- Infraestrutura física, envolvendo biblioteca e recursos de informação e comunicação; 
- $\quad$ Planejamento e avaliação;

- Políticas de atendimento aos estudantes e egressos; e

- Sustentabilidade financeira.

Entre os que contestam o sistema de autoavaliação, Da Silva (2007) é enfático ao afirmar que este processo, como hoje imposto, retira a titularidade da IES no mesmo, já que atende a determinações externas, às vezes estranhas à IES. Da maneira como hoje é implantada e desenvolvida a autoavaliação, pouco tem de características inerentes à IES que a ela procede; falta-lhe identidade própria já que assume contornos e padrões impostos de fora e, portanto, estranhos à sua realidade (DA SILVA, 2007; ARAÚJO; CORREIA, 2005; SOUSA; MARCONDES; ACOSTA, 2008; OSTRIA, 2000). Os próprios métodos e sistemas de autoavaliação, ainda, segundo estes autores, são criação externa (do MEC) e nem sempre representam a realidade da IES, vez que entre estas, as realidades são bem distintas e não refletem um padrão comum, compartilhado, que, se existente, facilitaria substancialmente o processo de autoavaliação e comparação de medidas entre elas.

Outro aspecto a destacar se refere à formação das Comissões Próprias de Avaliação (CPAs), estatuídas pela Lei no . 10.861/2004, que institui o SINAES. A realização da autoavaliação é de responsabilidade das CPAs, as quais possuem autonomia (fator contestado por alguns autores, como exposto mais acima) na IES, no que tange aos conselhos e demais órgãos colegiados. A CPA deverá ser composta por todos os segmentos da comunidade acadêmica (docentes, acadêmicos e corpo técnico-administrativo), bem como representantes da sociedade civil organizada, devendo sua composição ser de igual número de representantes para cada segmento. Consoante o exposto por Araújo e Correia (2005, p. 114) em relação às CPAs, a composição destas "coloca um retrocesso acerca do conceito de democracia demagogicamente aplicado nos primeiros artigos da lei". Por quê? Porque na conformação das CPAs, "apesar da lei prever a participação da sociedade civil organizada, não especifica parâmetros para a escolha dos segmentos representativos" (p.114) - um verdadeiro contrasenso que Tyler, Madaus e Stufflebeam (1989) já apontavam anos antes.

\subsubsection{A autoavaliação e seu subproduto: a qualidade}

Já se afirmava mais acima que a autoavaliação, dentre outros objetivos, busca estabelecer um padrão de qualidade na Educação Superior. Os resultados desse processo, em tese, poderiam redundar em melhoras nos níveis de qualidade, 
em amplo termo, ao permitirem aos gestores as necessárias correções de rota que derivassem em ações de aprimoramento educativo. Neste sentido, Ostria (2000, p. 163), em sua defesa do que denomina de "paradigmas da qualidade total, destaca pontual:

[...] Embora não são poucos os que consideram que a autoavaliação seria a contraparte do modelo político e a democracia universitária por seus conteúdos participativos, a maioria não concorda com esta visão e exalta a avaliação como um método para aproximar-se ao ideal de uma tomada de decisões racional, como prima nos modelos empresariais, o que a conecta, aparentemente, com os paradigmas da qualidade total.

A associação da autoavaliação com os atributos da qualidade universitária (no sentido daquela ser fundamental para o alcance desta) é defesa de vários autores (BERNHEIM, 2003; HORTAL, 2002; SARRICO; SANTOS, 2007; MORAES, 2001), dentre os quais Bernheim (2003, p. 167) destaca, em primeiro lugar, a complexidade da avaliação e da autoavaliação universitárias devido à sua multifuncionalidade e à necessidade de avaliar-se também "a adequação dos produtos de cada processo e dos processos em si”, o que torna mais crítica, ainda, sua autoavaliação. E complementa chamando a atenção especialmente para a autoavaliação da qualidade - diretamente ligada ao processo avaliativo e inerente a este - para o que traz as lições de Sonia Álvarez, da Universidade Nacional de Salta (Argentina), para quem a autoavaliação da qualidade, no marco do planejamento estratégico da Universidade, seria:

a) “[...] uma prática permanente, sistemática, institucional e intrínseca da universidade" atribuída aos atores envolvidos, e que "permite detectar os nós problemáticos e os aspectos positivos, e implica a reflexão permanente sobre a própria tarefa";

b) "[...] uma atividade cujo alcance tem a ver com os processos, os produtos e o impacto que ditos processos e produtos têm sobre a sociedade";

c) "[...] uma tarefa fundamental da gestão administrativa e acadêmica, que envolve as três funções universitárias de ensino, investigação e extensão", permitindo conhecer a realidade e sua relação com as metas planejadas, bem como "proceder a análises prospectivas e à geração de projetos alternativos";

d) "[...] uma tarefa que tem um caráter eminentemente construtivo, tendente a ajudar a detectar os déficit e dificuldades em matéria acadêmica, recursos físicos, docentes e técnicos", o que melhora a gestão institucional, tanto no desempenho como no alcance das metas, neutralizando-as ou superando-as; 
e) "[...] uma atividade que deve ser encarada tendo em conta os propósitos especificos do trabalho na Universidade, as condições institucionais particulares de sua história local e do contexto social" no qual se encontra, motivo que impõe a análise de aspectos qualitativos, e não apenas quantitativos;

f) "[...] uma tarefa coletiva que deve ser assumida coletivamente, de consenso em todas suas etapas, que inclua a todos os atores envolvidos em sua transformação”, tanto no diagnóstico como na interpretação dos resultados (das informações), fazendo igualmente coletiva a participação no desenho das políticas prospectivas e em sua execução.

Audi e Morosini (2008, p. 511) partem do princípio de que a qualidade educacional, em seu aspecto formal e lato, reside (ou melhor, deveria de residir), prioritariamente, no corpo docente das universidades, posto que é daqui que egressarão os profissionais em amplo termo, inclusive aqueles que irão lidar com a função docente em todos os níveis da educação formal. Em base a esta premissa, estes autores conceituam a qualidade como sendo "um processo multifacetário, envolvendo questões de ordem teórica, profissional, atitudinal, valorativa e contextual, sociocultural e política". Portanto, a construção de indicadores de qualidade é objeto-processo dinâmico, e não "uma aquisição estática de indicadores vistos como produto", acrescem estes autores, complementando: "A qualidade da educação, assim configurada, é permeada por juízo de valor, envolvendo uma aspiração a ser alcançada de forma processualística". Entretanto, se estes autores ora citados se referem à qualidade formal como fundamento da educação superior (e de todos os níveis), há outros autores que analisam a qualidade no sentido de um diferencial competitivo estratégico da IES, em seu esforço para conquistar e manter mercados, hoje muito mais disputados do que ontem.

Cobra e Braga (2007, p. 29-30), por outro ângulo mais afeto ao conceito de qualidade total, consideram o corpo docente da IES como um elemento-chave "para a imagem de qualidade percebida da instituição", sublinhando complementarmente que: "boas instalações, bons professores e estrutura curricular adequada são sinônimo de qualidade institucional, e que, se bem divulgados, serão percebidos pelo público como elementos de valor"; mas, sob outro olhar, estes indicadores não podem mais ser entendidos como diferenciais competitivos já que são condições inerentes, fundamentais e obrigatórias de toda e qualquer instituição. Esses diferenciais, ainda, "não criam posicionamento e não são suficientes para influenciar a decision making (tomada de decisão de compra)", completam estes autores. 
Marback Neto (2007, p. 20), também enfocando a qualidade, situa o processo de autoavaliação institucional como elemento fundamental para a capacidade competitiva das IES e também "como instrumento de qualidade na gestão universitária" no sentido de que a eficiência da avaliação, bem como "a disposição dos dirigentes em torná-la eficaz farão a diferença qualitativa na gestão. Se não há sincronia entre os diversos grupos da universidade e falta profissionalismo para a consecução de objetivos, a qualidade passa a ser inatingível", fundamentando ainda:

E sem qualidade, que se traduz num conjunto de condições de eficácia compatível com as exigências de nosso desenvolvimento, a universidade no Brasil persistirá como adverte Giannotti num texto de 1985 funcionando para não funcionar, isto é, não está cumprindo nem mesmo os padrões de funcionamento mínimo. O que é uma contrafação. Ou uma caricatura.

Sordi (2002, p. 65-66), de outro lado, tece críticas severas ao processo de avaliação como sendo garantia de qualidade, seguindo uma premissa que afirma: "quanto mais se avalia, mais se caminha na direção da pós-modernidade". Segundo esta autora, no afã de "provar" sua transparência/qualidade, as IES "entregam-se às práticas avaliativas externas, ansiosas por obter boas notas", as quais, quando divulgadas, provêem a IES visibilidade institucional que redunda em captação de novos alunos. Esta necessidade de captação de novos "clientes" tanto é expressa no processo de auto-observação (autoavaliação institucional), como no processo de observação externa (avaliação institucional). Sordi (2002, p. 66) questiona a respeito: “A quem pertence a legitimidade de conceber um projeto de educação? Por que estão se avaliando? Para quem os dados são construídos (por vezes fabricados)? Qual o uso que se pretende fazer deles findo o ritual sumário da emissão dos conceitos?". Esta autora atribui tais estratégias não em função da necessária qualidade dos serviços prestados, mas sim, no seu "forte conteúdo político e econômico".

Outro estudo interessante sobre o tema da qualidade e sua relação com o processo de avaliação (interna e externa) é o apresentado por Leite et al (2007, p. 672-686). Primeiramente, estes autores se referem ao entendimento dos alunos em relação ao processo de avaliação institucional, considerado por estes legítimo como acompanhamento da qualidade, enquanto o modo de fazer a avaliação é considerado ilegítimo. Os autores consideram este impasse como um "nó de entendimento das representações sobre avaliação institucional". A ilegitimidade do modo de fazer criticado pelos alunos se deve a que esse pro- 
cesso não considera "a produção do conhecimento, a sua divulgação e a eficácia das instituições", complementando os autores destacam que:

Os resultados das avaliações legítimas deveriam ser amplamente divulgados e aplicados e a avaliação seria boa para conhecer e manter o padrão de qualidade do ensino e melhorar o posicionamento da instituição com obtenção de boas notas. A qualidade dos cursos, dos docentes, da infra-estrutura e da universidade como um todo, serve para aprimorá-la e favorece um retorno para a coletividade.

Assim, a avaliação institucional pode ser entendida "como uma forma de diagnóstico da qualidade do ensino, para que todos saibam as reais condições das universidades; para identificar suas falhas, pontos fortes e fracos" (LEITE et al, 2007, p. 672). Portanto, o requisito da qualidade, como pode ser observado pelas exposições dos autores referenciados neste ponto, é fundamental e está intimamente conectado aos processos de avaliação e de autoavaliação institucional, nas universidades em sentido lato.

\subsection{O Processo Decisório nas IES}

O processo de tomada de decisão (em seu sentido genérico) se sustenta em pilares sólidos, como: a certeza na escolha de uma opção; a rapidez em se realizar essa escolha; a proatividade decisória (e não reatividade); o compartilhamento de informações em tempo real; a iniciativa individual e, por decorrência, coletiva, dentre outros aspectos que aparecem como vitais ao momento de decisão. $\mathrm{O}$ fundamento de todo esse processo (decisório), em suma, está referenciado num conceito mais amplo de sinergia, claramente desenhado por Blake e Moulton (apud VILLAS BÔAS, 2008, p. 107):

A organização é uma entidade empresarial integrada. Seus membros e setores devem agir não apenas independentemente, mas também inter-dependentemente a fim de alcançar a excelência. Essa afirmação é fundamental. Uma vez entendido que o todo pode ser maior e diferente que a soma de suas partes, reconhece-se a possibilidade de uma atuação sinérgica.

Rizzati e Dobes (2004, p. 2) destacam que existem alguns modelos teóricos de maior destaque para o governo acadêmico: o burocrático, o colegiado, o político e o chamado de anarquia organizada. A escolha pela forma de governo é que invariavelmente determinará a ação a ser empreendida para influenciar o 
processo decisório: uso de legislação como base na argumentação, persuasão, coalizão e ações individuais. O processo decisório em IES não parece, assim, nada simples; ao contrário, mostra complexidade e diversidade, na medida em que cada instituição segue seus próprios padrões e atende às suas próprias demandas. Não há, portanto, como afirmar que exista um processo decisório padrão ou estandardizado, o que seria utópico. Como afirma Villas Bôas (2008, p. 104), em termos de planejamento estratégico e processo decisório em IES, "não existe receita de bolo". Suas características básicas, entretanto, devem estar presentes: "orgânico, desburocratizado, aberto à absorção das características de cada instituição e desenvolvido sob medida ao DNA e à cultura imperativa em cada organização". Adicionalmente, merece citar-se outro detalhe igualmente importante: a autoridade do poder decisório deve estar "nas mãos dos que estão perto das fontes de informação e nas mãos dos que têm know-how para interpretá-las e agir conforme a situação demanda" (TENÓRIO, 2007, p. 28). Em todo caso (e em última instância), o fato de decidir algo sempre implica (e sempre implicará) deixar de fora outra opção que se encontrava disponível para tal, o que significa a necessidade de escolha, consciente e inteligente, fundamentada em amplo debate, embora nunca seja possível esgotar todas as possibilidades de se cometer um erro.

\section{ASPECTOS METODOLÓGICOS}

Formulou-se, para os fins desta pesquisa, um estudo do tipo descritivoexploratório, para descrever características de determinados fenômenos (autoavaliação e processo de tomada de decisão) e também por permitir ao pesquisador familiarizar-se com um problema para torná-lo explícito (GIL, 1991). Em relação ao método, esta pesquisa utilizou um estudo quali-quantitativo, visto que enseja uma relação dinâmica entre o mundo real e o sujeito, parcialmente traduzível em números, mas acessível à atribuição de significados mediante uma análise indutiva dos dados coletados em campo (GIL, 1991; GRILLO; MEDEIROS, 1998).

A preocupação maior da abordagem qualitativo-descritiva é descrever os dados que configuram um determinado fenômeno humano, preocupando-se com a qualidade da análise e "com o nível de realidade que não pode ser quantificado". (MINAYO, 2003, p. 21). Buscando identificar as múltiplas facetas de um objeto de pesquisa, porém, sem distorcer a realidade, neste sentido Gil (2006, p. 21) corrobora: 
A pesquisa qualitativa, nas ciências sociais, se preocupa com o nível de realidade que não pode ser quantificado. Ela trabalha com o universo de significados, crenças, aspirações e atitudes, que não podem ser reduzidos à operacionalização de variáveis. A diferença entre qualitativo e quantitativo é de natureza. O conjunto desses dados não se opõe. Ao contrario, se complementa, pois a realidade abrangida por eles interage, excluindo qualquer dicotomia.

Portanto, verifica-se que a pesquisa quali-quantitativa tem o ambiente natural como sua fonte direta de dados e não, necessariamente, laboratórios ou ambientes de pesquisa controlados. Nesta forma de abordagem qualitativa, o procedimento de coleta de dados é diversificado, podendo ser observação direta, observação participante, entrevistas, análise de documentos, depoimentos, histórias de vida entre outros. Por esta razão, a abordagem do problema é através da pesquisa quali-quantitativa, considerando que existe uma relação dinâmica entre o fato em estudo e o sujeito, enfatizando a necessidade da interpretação do fenômeno e a atribuição de significado como fundamentais nesta abordagem.

Na procura de respostas para as questões deste estudo, visando alcançar os objetivos, verificou-se também o direcionamento para um estudo de caráter exploratório (VIEIRA; ZOUAIN, 2006; TACHIZAWA; MENDES, 2006) com a aplicação de uma pluralidade de procedimentos para coleta de dados, tais como, pesquisas bibliográficas, pesquisa documental, estudo de caso e estudo de casos múltiplos ou multicaso. A opção pela escolha desses procedimentos deve-se ao entendimento de que sua conjugação traz mais objetivo ao trabalho, proporcionando maior fidedignidade ao seu resultado.

Ainda em relação à metodologia, a intenção do pesquisador com a pesquisa bibliográfica foi a de embasar seus estudos metodológicos com a teoria, calcada em autores que já produziram literatura acerca de seu tema de pesquisa. Seu objetivo é "desvendar, recolher e analisar as principais contribuições sobre um determinado fato, assunto ou idéia" (GALLIANO, 1996, p. 109). De outra parte, utiliza-se a pesquisa documental, pois são analisados os procedimentos da Autoavaliação, do Plano de Desenvolvimento Institucional (PDI) e do Regimento das Faculdades SENAC/SC. Conforme a Associação Brasileira de Normas Técnicas (ABNT, 2002, p. 2) a pesquisa documental é desenvolvida sobre "qualquer suporte que contenha informação registrada, formando uma unidade, que possa servir para consulta, estudo ou prova. Inclui impressos, manuscritos, registros audiovisuais, sonoros, magnéticos e eletrônicos, entre outros". 
Considerando-se que a metodologia utilizada na pesquisa é qualitativa e seu caráter descritivo, tem-se o design de estudo de caso. O estudo de caso como estratégia de pesquisa pode ser utilizado de modo descritivo, com objetivo de aprofundar a descrição de determinada realidade (TRIVIÑOS, 1987). O estudo de caso pode abranger registros, entrevistas estruturadas e não-estruturadas, observações de acontecimentos ou qualquer outra técnica de pesquisa. O estudo de caso, segundo Gil (1991), envolve estudo profundo de um ou poucos objetos, de maneira a obter-se o seu amplo e detalhado conhecimento. Portanto, como são estudados mais de um caso, a presente pesquisa caracteriza-se como um estudo multicaso. A pesquisa de estudo de casos múltiplos ou multicaso, pode apresentar vantagens e desvantagens, podendo as evidências apresentadas ser consideradas mais convincentes e o resultado final do estudo com mais propriedade. Já o fundamento lógico apresentado em caso único, dificilmente será satisfeito por casos múltiplos (YIN, 2001). A título de complementação, adicione-se que esta pesquisa pode ser qualificada como sendo de corte transversal, ou seja, realizada em junho e julho de 2010.

Em relação à hipótese proposta - "A autoavaliação institucional, quando instituída em uma instituição, influencia, com a provisão de subsídios, o processo de tomada de decisão" - esta, em razão da sua estruturação e conteúdo, pode ser classificada como indutiva e analógica, visto que se baseia na semelhança entre os fenômenos que se desejam explicar e outros já conhecidos (CIRIBELLI, 2003). Explicando: todo processo decisório, em tese, possui fundamento na coleta de dados de uma organização, internos e externos, a fim de prover subsídios àquele para decidir-se por determinada ação. A autoavaliação nada mais é que um processo de levantamento de dados e informações internas da instituição, que também espelham situações externas possibilitando sustentar determinadas escolhas decisórias em termos estratégicos. Isto é comum a toda organização, servindo de base, portanto, para a analogia e a indução.

\section{RESULTADOS}

Este estudo formulou, em sua proposta, o seguinte problema: Considerandose que a autoavaliação institucional (AVI), segundo a literatura pertinente, influencia no processo de tomada de decisão das IES, pergunta-se: (a) Há indicadores precisos dessa influência no processo decisório das Faculdades SENAC/SC? (b) Se a resposta à questão anterior for positiva, como se dá essa influência? Em outras palavras, tratava-se de verificar a relação existente (se é que ela existe) entre a AVI e o processo de tomada de decisão, destacando em caso de existência, qual a maneira de dar-se essa influência. 
Após análise dos dados coletados a partir da pesquisa aplicada, e anteriormente discutidos, pode-se identificar potencialidades e fragilidades, que foram compilados e apresentados na tabela abaixo:

\section{Tabela 1- Apresentação das Potencialidades e Fragilidades identificadas na pesquisa}

\begin{tabular}{l|l}
\hline Potencialidades & Fragilidades \\
\hline $\begin{array}{l}\text { Alto grau de importância da } \\
\text { autoavaliação (81\%). }\end{array}$ & $\begin{array}{l}\text { 35\% dos respondentes acreditam que a } \\
\text { autoavaliação não traduz a realidade institucional. }\end{array}$ \\
\hline $\begin{array}{l}\text { Confiabilidade das informações } \\
\text { derivadas da autoavaliação (77\%) }\end{array}$ & $\begin{array}{l}\text { Necessidade de melhoria no instrumento de coleta } \\
\text { de dados da autoavaliação (61,5\%). }\end{array}$ \\
\hline $\begin{array}{l}\text { 96\% dos pesquisados concordam } \\
\text { que a ferramenta da autoavaliação } \\
\text { possibilita melhorias na instituição. }\end{array}$ & $\begin{array}{l}\text { 46\% dos respondentes consideram que os } \\
\text { resultados da autovaliação não são levados em } \\
\text { conta no momento da tomada de decisão. }\end{array}$ \\
\hline $\begin{array}{l}\text { Necessidades de melhoria apontadas } \\
\text { na autoavaliação são atendidas } \\
\text { (81\%). }\end{array}$ & $\begin{array}{l}\text { 50\% dos pesquisados afirmam ser falha a difusão } \\
\text { das informações obtidas através da autoavaliação. }\end{array}$ \\
\hline $\begin{array}{l}\text { Participação efetiva dos diferentes } \\
\text { grupos de usuários da autoavaliação } \\
\text { (73\%). }\end{array}$ & $\begin{array}{l}70 \% \text { dos respondentes acreditam que os } \\
\text { resultados da autoavaliação não atendem a todos } \\
\text { os níveis de tomadores de decisão. }\end{array}$ \\
\hline $\begin{array}{l}\text { Todas as dimensões apresentadas } \\
\text { pelo CONAES (com exceção das } \\
\text { dimensões 2 e 7) apresentam índice } \\
\text { acima de 60\% indicando facilidades } \\
\text { nestes processos. }\end{array}$ & $\begin{array}{l}\text { Itens positivos são mantidos, mas não entram no } \\
\text { processo decisório. }\end{array}$ \\
\hline $\begin{array}{l}\text { 60\% dos entrevistados confirmam } \\
\text { que a maioria das propostas de } \\
\text { melhorias derivadas da autoavaliação } \\
\text { institucional fazem parte do } \\
\text { orçamento da unidade. }\end{array}$ & $\begin{array}{l}\text { 69\% dos pesquisados afirma que a tomada de } \\
\text { decisão está diretamente ligada as características } \\
\text { de cada unidade. }\end{array}$ \\
\hline & $\begin{array}{l}\text { Dificuldade no processo decisório no que diz } \\
\text { respeito as dimensões 2 e 7 (CONAES - Política } \\
\text { de Ensino, Pesquisa e Extensão e Infraestrutura } \\
\text { Física, respectivamente). }\end{array}$ \\
\hline $\begin{array}{l}\text { Descompasso temporal entre ações apontadas } \\
\text { pela autoavaliação e o processo decisório } \\
\text { (Dimensões } 7 \text { e 8 CONAES). }\end{array}$ \\
\hline
\end{tabular}

Fonte: autores 
A síntese apresentada no quadro demonstra especialmente nas potencialidades que os gestores percebem a importância da autoavaliação institucional, existindo confiabilidade no processo e creditando ao mesmo a possibilidade de servir de base para propor melhorias na performance da instituição. Todavia, percebe-se também um olhar crítico relacionado ao instrumento de pesquisa utilizado, evidenciando que existe a vontade de acertar.

Por outro lado, o fato de que nas fragilidades foram apontados um percentual de $35 \%$ dos gestores afirmando que os resultados da autoavaliação não traduzem a realidade institucional, podendo remeter a crítica feita ao instrumento utilizado, onde $61,5 \%$ dos pesquisados respondeu sim pela reformulação do mesmo, evidenciado nas respostas discursivas da seguinte forma: "o instrumento merece uma revisão", "atualmente o instrumento de pesquisa está falho e confuso" ou ainda "o questionário atual da autoavaliação não está completamente adequado a realidade da faculdade", outro fator que pode denotar tal fragilidade é a falta de cultura avaliativa. Neste sentido, importante frisar que o processo autoavaliativo do SINAES é novo, não sendo diferente para as Faculdades de Tecnologia do Senac, podendo ser um dos motivos pelos quais $46 \%$ dos seus gestores não levam em conta os resultados da autoavaliação no momento da tomada de decisão e outros $70 \%$ afirmam que os resultados não atendem a todos os níveis de tomadores de decisão, fazendo desta forma com que ainda não o considerem como um processo relevante para uma gestão qualificada e sim em processo de aculturamento.

Os resultados da pesquisa também demonstram que há o envolvimento e participação efetiva de vários grupos de usuários, o que por si só confirma a preocupação com a participação de todos os atores no processo autoavaliativo.

No entanto, também ficou ratificado por 50\% dos entrevistados que há falha na disseminação dos resultados obtidos na autoavaliação institucional, o que por sua vez pode justificar a afirmação de que seus resultados não atendem a todos os níveis de tomadores de decisão, podendo configurar-se como falta de acesso a estes resultados, esta confirmação só poderia ser validade através de um levantamento para tal.

Com relação às dimensões de análise sugeridas pela CONAES, apenas as dimensões 2 e 7 (Política de Ensino, Pesquisa e Extensão e Infraestrutura Física, respectivamente), foram citadas como apresentando aos gestores, dificuldades no momento de tomada de decisão, o que pode ser justificado 
por serem dimensões que exijam do gestor aporte de investimentos, que possivelmente necessite de liberação em níveis hierárquicos superiores.

Assim, pode-se afirmar, que não há indicadores precisos que apontem a influência maciça da autoavaliação institucional sobre o processo decisório. Os entrevistados ainda demonstram muitas dúvidas a este respeito, além de questionarem a estrutura atual do sistema de autoavaliação institucional, a disseminação democrática dos dados e informações derivados da AVI e sua aplicabilidade na prática.

Por outro lado, o pressuposto da influência da autoavaliação institucional sobre o processo de tomada de decisão, a despeito de dúvidas que ainda pairam sobre tal influência, acabou sendo validada pelas respostas, vez que esta ficou comprovada, mesmo que não nos níveis em que se esperaria que acontecesse.

Um aspecto adicional que merece menção (e atenção) é o elevado número de não-respondentes, o que induz a inferir-se que pairam muitas dúvidas e incertezas, entre os colaboradores das Faculdades SENAC/SC, na provável relação entre a AVI e o processo decisório e, mais ainda, na positividade prática da AVI. Ou por esta estar mal-formulada, ou porque não se estão aplicando devidamente seus dados e informações, em tempo hábil e na direção certa. Parece ser, em suma, um problema de gestão.

Não se nega a positividade que a ferramenta autoavaliativa institucional traz às organizações que dela se servem para fundamentar seus processos decisórios estratégicos; ao contrário, sabe-se bem, através das experiências elencadas no trabalho dissertivo original que deu lugar a este artigo, da sua importância como auxílio efetivo às decisões estratégicas. A questão, portanto, não reside no nível de relevância ou irrelevância desta ferramenta, mas sim, na estrutura adequada da AVI e na consequente aplicabilidade de seus resultados num timing condizente com a celeridade das mudanças de um mercado hoje global.

A contribuição pretendida foi atendida, no sentido de propiciar aos leitores desta investigação uma análise fechada sobre a realidade setorizada da instituição em estudo, no momento atual, permitindo que, a partir destas inferências, se possam desenvolver novos estudos, mais aprofundados nos pontos considerados críticos ou que identificam problemáticas gestoras, interpretações errôneas das questões-chave, "gaps" ${ }^{1}$ na compreensão da relação entre variáveis (como processo decisório, autoavaliação institucional etc.).

$\overline{1 \mathrm{GAP}}=$ do inglês: lacuna, vazio. 


\section{CONCLUSÕES}

Primeiramente, é clara a importância dada pelos entrevistados para o processo de autoavaliação institucional. Praticamente toda a amostra concordou neste sentido, a grande maioria atribui-lhe o conceito de "alta importância". Entretanto, pelas respostas subseqüentes infere-se que, apesar da elevada relevância dada a esta ferramenta gestora, há opiniões expressas que a criticam como "falha, confusa, com muitas brechas", embora os entrevistados não neguem a confiabilidade dos dados e informações derivadas da AVI.

Levada para o cenário do processo de tomada de decisão, para ver se tais informações são efetivamente utilizadas neste, observou-se praticamente um empate técnico entre os que afirmam assim ser e os que negam ou aduzem a que apenas "às vezes" ela serve ao processo decisório. Há questionamentos a respeito, inclusive nas respostas discursivas que esta questão permitia realizar. Daí a compreender-se que a maioria dos respondentes tenha afirmado existir necessidade de se reformular o processo de AVI e, adicionalmente, de se fazer conhecidos seus resultados por todos os usuários de informações, já que uma considerável parcela alega não ter o referido acesso. Este resultado é ratificado pela maioria dos entrevistados (quando questionados sobre o atendimento dessas informações em todos os níveis de tomadores de decisão) que negam ocorrer dessa forma a disseminação informativa, prejudicando o processo decisório. Similar resultado (negativo) coube também à afirmativa de que o processo decisório depende integralmente da AVI e, mais adiante, à maioria que afirma que nem todos os resultados da AVI são considerados no processo decisório ou, ainda, aos $77 \%$ de respondentes que afirmaram serem as ações e reações do mercado que fundamentam o processo decisório.

Embora sejam evidentes os indicativos que apontam para a existência de certa influência dos resultados derivados do processo de autoavaliação sobre o processo decisório, não há como se negar que, neste caso específico das Faculdades de Tecnologia SENAC-SC, existem ainda necessidades de ajuste daquele processo autoavaliativo, a fim de atender aos seus objetivos e a toda a comunidade acadêmica a que serve.

Afinal, deve relevar-se que todo e qualquer processo decisório é considerado como ponto crítico na gestão de organizações, sejam estas educativas ou não, o que demanda que suas fontes informativas que o alimentam sejam confiáveis e bem fundamentadas. A relação entre avaliação e decisão, assim, devem acontecer em bases sólidas, sob pena daquela (avaliação) prejudicar esta (decisão). E uma decisão mal-fundamentada pode se tornar em grave inconveniente para a sustentabilidade estratégica da instituição. 
Por fim, a título de sugestão, toma-se a liberdade de sugerir a outros investigadores interessados no desempenho das Faculdades SENAC e até de outras instituições de educação tecnológica, a elaboração de investigações mais profundas e com foco mais limitado que permitam detectar, em detalhes, onde se encontram os principais problemas que envolvem a relação entre o processo de autoavaliação institucional e seu subsequente processo decisório.

\section{REFERÊNCIAS}

ABNT - ASSOCIAÇÃO BRASILEIRA DE NORMAS TÉCNICAS. Comitê Brasileiro de Informação e Documentação. Comissão de Estudo e Documentação. NBR 6023. Informação e documentação: referências elaboração. Brasília: ABNT, 2002.

ARAÚJO, Josemeire de Omena; CORREIA, Maria Valéria Costa (Orgs.). Reforma universitária: a universidade pública em questão. Maceió: EDUFAL, 2005.

AUDI, Jorge Luis Nicolas; MOROSINI, Marília Costa (Orgs.). Inovação e qualidade na universidade $=$ Innovation and Qualtiy in the University. Porto Alegre: EDIPUCRS, 2008.

BERNHEIM, Carlos Tünnermann. La universidad ante los retos del siglo XXI. Yucatán, México: Mérida, 2003.

BRASIL.Ministério da Educação. Instituto Nacional de Estudos e Pesquisas Educacionais Anísio Teixeira (INEP). Censo da educação superior 2007. Brasília: MEC, 2009. Resumo técnico.

Sistema Nacional de Avaliação da Educação Superior - SINAES. Lei no 10.861/2004. Brasília: MEC, 2004.

BRUNNER, José Joaquín. Nuevas demandas y sus consecuencias para la educación superior en América latina. Trabajo preparado para el Proyecto de CINDA, en colaboración con IESALC/UNESCO, sobre "Demandas Sociales y sus Implicancias para la Educación Superior". Santiago de Chile: Escuela de Gobierno de la Universidad Adolfo Ibáñez y el Departamento de Ingeniería Industrial de la Facultad de Ciencias Físicas y Matemáticas de la Universidad de Chile, mayo 2002. 
CARDOSO, Rodolfo; SANTOS, João Alberto Neves dos; FIGUEIREDO, Moacyr Amaral D. O impacto das práticas de liderança no desempenho da organização: a aplicação prática da metodologia desenvolvida.In: ENCONTRO NACIONAL DE ENGENHARIA DE PRODUÇÃO. 23.,2002, Florianópolis. Anais... Florianópolis, 2002. CD Rom.

CIRIBELLI, Marilda Corrêa. Como elaborar uma dissertação de mestrado através da pesquisa científica. Rio de Janeiro: 7 Letras, 2003.

COBRA, Marcos; BRAGA, Ryon. Marketing educacional: ferramentas de gestão para instituições de ensino. São Paulo: Cobra Editora \& Marketing, 2007.

CUNHA, Maria Isabel da (Org.). Formatos avaliativos e concepção de docência. Campinas: Autores Associados, 2005.

DA SILVA, Janssen Felipe. Modelo de formação de pedagogos(as) professores(as) e políticas de avaliação da educação superior. Recife: UFPE, 2007.

DIAS SOBRINHO, José. Avaliação da educação superior. Petrópolis: Vozes, 2000. Avaliação da educação superior: regulação e emancipação. Avaliação, Campinas, v. 8, n. 1, p. 31-47, mar. 2003.

DUCH, Maria Angela Brescia Gazire. Estudo da implementação de cursos superiores de tecnologia. In: SEMINÁRIO NACIONAL DE EDUCAÇÃO PROFISSIONAL E TECNOLÓGICA, 1., 2010. Belo Horizonte. Disponível em: < http://www.senept.cefetmg.br/galerias/Arquivos_senept/anais/quarta_ tema3/QuartaTema3Artigo6.pdf>. Acesso em: 25 mar. 2011.

ELPO, Mirian E. H. Collares. Avaliação da gestão universitária: velhos problemas e novas perspectivas. In: COLÓQUIO INTERNACIONAL SOBRE GESTÃO UNIVERSITÁRIA NA AMÉRICA DO SUL,4., 2004, Florianópolis. Disponível em: < http://www.inpeau.ufsc.br/coloquio04/ completos/Mirian\%20E.\%20H.\%20Collares\%20Elpo\%20-\%20 Avalia\%E7\%E3o\%20da\%20Gest $\% E 30 \% 20$ Universit\%E1r.doc $>$. Acesso em: 23 mar. 2011.

FURTADO, Ribamar; FURTADO, Eliane. A intervenção participativa dos atores - INPA - Uma metodologia de capacitação para o desenvolvimento local sustentável. Brasília (DF): IICA, 2000. 
GALLIANO, Alfredo Guilherme. O método científico: teoria e prática. São Paulo: Harbra, 1996.

GATTI, Bernardete A. Avaliação Institucional de Universidade. In: STEINER, João E.; MALNIC, Gerhard (Orgs.). Ensino superior: conceito e dinâmica. São Paulo: EDUSP, 2006.

GIL, Antonio Carlos. Como elaborar projetos de pesquisa. São Paulo: Atlas, 1991.

Pesquisa social. São Paulo: Atlas, 2006.

GRILLO, Marlene; MEDEIROS, Marilú Fontoura (Org.). A construção do conhecimento e sua mediação metodológica. Porto Alegre: EDIPUCRS, 1998.

HORTAL, Jesus. A Universidade: realidade e esperança. São Paulo: Edições Loyola, 2002.

KRASILCHIK, Myriam. Gestão: desafios e perspectivas. Revista USP, São Paulo, n. 78, p.22-31, jun./ago. 2008. Disponível em: <http:// www.revistasusp.sibi.usp.br/scielo.php?script=sci_arttext\&pid=S010399892008000300004\&lng=pt\&nrm=iso>. Acesso em: 20 mar. 2011.

LEITE, Denise et al. Estudantes e avaliação da universidade: um estudo conjunto Brasil - Portugal. Cadernos de Pesquisa, São Paulo, v. 37, n. 132, p. 661-686, set./dez. 2007. Disponível em: < http://www.scielo.br/pdf/cp/ v37n132/a0837132.pdf>. Acesso em: 14 mar. 2011.

LUCKESI, Cipriano Carlos. Filosofia da educação. São Paulo: Cortez, 1994.

MARBACK NETO, Guilherme. Avaliação: Instrumento de gestão universitária. Vila Velha, ES: Hoper, 2007.

MARTINS, Anderson Antônio Mattos; GARIBA JÚNIOR, Maurício. Um modelo de avaliação de cursos superiores de tecnologia baseado na ferramenta benchmarking. In: CONGRESSO BRASILEIRO DE ENSINO DE ENGENHARIA, 4., 2006, Passo Fundo. Disponível em: <http://www. dee.ufma.br/ fsouza/anais/arquivos/8_128_655.pdf >. Acesso em: 13 set. 2010 . 
MENESES, Pedro Paulo Murce; ABBAD, Gardênia. Preditores individuais e situacionais de auto e heteroavaliação de impacto do treinamento no trabalho. Revista de Administração Contemporânea, Curitiba, p. 185-204, 2003. Edição especial.

MINAYO, Maria Cecília de Souza. Pesquisa Social: teoria, método e criatividade. Vozes: Petrópolis, 2003.

MORAES, Flávio Fava de. Avaliação institucional. In: CALDAS, M. J. (Org.). A USP e seus desafios: Fórum de Políticas Universitárias. São Paulo: EDUSP, 2001.

MURIEL, Roberta. Plano de Desenvolvimento Institucional - PDI. Análise do processo de implantação. Brasil: Hoper, 2006.

OSTRIA, Gustavo Rodríguez (Org.). De la revolución a la evaluación universitaria: cultura, discurso y políticas de educación superior en Bolivia. La Paz , Bolívia: FUNDACIÓN PIEB, 2000.

POLIDORI, Marlis Morosini; MARINHO-ARAUJO, Claisy M.; BARREYRO, Gladys Beatriz. SINAES: perspectivas e desafios na avaliação da educação superior brasileira. Ensaio: avaliação e políticas públicas em educação, Rio de Janeiro, v. 14, n. 53, p. 425-436, 2006. Disponível em: <http://www.scielo.br/scielo.php?pid=S010440362006000400002\&script=sci_arttext\&tlng=pt $>$. Acesso em: 20 mar. 2011.

RIZZATI, Gerson; DOBES, Cantalícia Elaine I. A complexidade do processo decisório em universidades. In: MELO, Pedro Antônio; COLOSSI, Nelson. (Org.). Cenários da gestão universitária na contemporaneidade. Florianópolis: Insular, 2004.

SANTOS, João Alberto Neves dos; ROLIM, Carlos Augusto. Metodologia para a autoavaliação organizacional: aplicações ao serviço público. Rio de Janeiro: Instituto Militar de Engenharia, 1999.

SARRICO, Claudia; SANTOS, Isabel. Estudantes e avaliação da universidade. Cadernos de Pesquisa, São Paulo, v. 37, n. 132, set./dez. 2007.

SGUISSARDI, Valdemar (Org.). Avaliação universitária em questão: reformas do estado e da educação superior. Campinas: Autores Associados, 1997. 
SORDI, Mara Regina Lemes de. Entendendo as lógicas da avaliação institucional para dar sentido ao contexto interpretativo. In: VILLAS BOAS, Benigna, M. de F. (Org.). Avaliação: políticas e práticas. Campinas: Papirus, 2002.

SOUSA, Clarilza Prado de; MARCONDES, Anamérica Prado; ACOSTA, Sandra Ferreira. Auto-avaliação institucional: uma discussão em processo. Associação Brasileira de Avaliação Institucional - ABAVE. Revista Estudos em Avaliação Institucional, São Paulo, v. 19, n. 39, jan./abr. $2008 .$.

TACHIZAWA, Takeshy; MENDES, Gildásio. Como fazer monografia na prática. 12. ed. Rio de Janeiro: FGV, 2006.

TENÓRIO, Fernando Guilherme. Tecnologia da informação transformando as organizações e o trabalho. Rio de Janeiro: FGV, 2007.

TRIVIÑOS, Augusto N.S. Introdução à pesquisa em ciências: a pesquisa qualitativa em educação. São Paulo: Atlas, 1987.

TYLER, Ralph Winfred; MADAUS, George F.; STUFFLEBEAM, Daniel L. Educational evaluation: classic works of Ralph W. Tayler. Evaluation in Education and Human Services. New York: Springer, 1989.

VIEIRA, Marcelo Milano Falcão; ZOUAIN, Deborah Moraes. (Org.). Pesquisa qualitativa em administração. Rio de Janeiro: FGV, 2006.

VILLAS BÔAS, Rafael. The campus experience: marketing para instituições de ensino. São Paulo: Summus; Hoper, 2008.

WITTMANN, Lauro Carlos; GRACINDO, Regina Vinhaes (Coords.). O estado da arte em política e gestão da educação no Brasil - 1991 - 1997. Campinas: Autores Associados, 2001.

YIN, Robert. K. Estudo de caso: planejamento e métodos. Porto Alegre: Bookman, 2001. 